\title{
A Study of Dykstra-Parsons Curves
}

SUPRI TR 29

\section{By}

A.O. deSouza

W.E. Brigham

February 1995

Work Performed Under Contract No. DE-FG22-93BC14899

Prepared for

U.S. Department of Energy

Assistant Secretary for Fossil Energy

Thomas B. Reid, Project Manager

Bartlesville Project Office

P.O. Box 1398

Bartlesville, OK 74005

Prepared by

Stanford University

Petroleum Research Institute

Stanford, CA 94305-2220

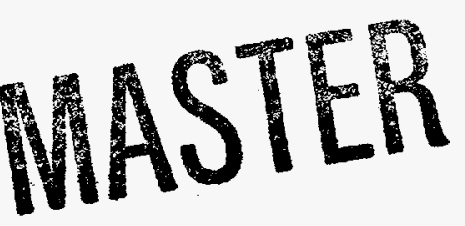




\section{DISCLAIMER}

This report was prepared as an account of work sponsored by an agency of the United States Government. Neither the United States Government nor any agency thereof, nor any of their employees, make any warranty, express or implied, or assumes any legal liability or responsibility for the accuracy, completeness, or usefulness of any information, apparatus, product, or process disclosed, or represents that its use would not infringe privately owned rights. Reference herein to any specific commercial product, process, or service by trade name, trademark, manufacturer, or otherwise does not necessarily constitute or imply its endorsement, recommendation, or favoring by the United States Government or any agency thereof. The views and opinions of authors expressed herein do not necessarily state or reflect those of the United States Government or any agency thereof. 


\section{DISCLAIMER}

Portions of this document may be illegible in electronic image products. Images are produced from the best available original document. 


\section{TABLE OF CONTENTS}

\section{Page}

List of Figures

iv

Acknowledgement

iv

Abstract

v

1. Introduction

2. Mathematical Formation for a Layered System

2.1 Piston-Like Displacement

2

2.2 Modifications to the Calculational Approach

3. Dykstra-Parsons Permeability Distribution

4. Empirical Correlation

5. Conclusions 24

6. References 


\section{LIST OF FIGURES}

1. Two-layered waterflood displacement

Page

2. Water/oil ratio history for $M<1$

3. Water/oil ratio history for $M>1$

4. Log-normal permeability distribution graph

5. Coverage curves for $\mathrm{WOR}=0.1$

6. Coverage curves for $W O R=0.2$

7. Coverage curves for $W O R=0.5$

8. Coverage curves for $W O R=1.0$

9. Coverage curves for $W O R=2$

10. Coverage curves for $W O R=5$

11. Coverage curves for $W O R=10$

12. Coverage curves for $W O R=25$

13. Coverage curves for $W O R=50$

14. Coverage curves for $\mathrm{WOR}=100$

15. Water/oil ratio histories for permeability variation, $V=0.5$

16. Effect of adding 0.4 to water/oil ratio curves, $V=0.5$

17. Final correlation of Dykstra-Parsons recovery curves

\section{ACKNOWLEDGEMENTS}

The authors are grateful for the financial support from the Stanford University Petroleum Research Industrial Affiliates and Department of Energy, Grant No. DE-FG22-93BC14899. Major additional support was provided to the first author by PETROBRAS, his country's oil company. 


\begin{abstract}
The Dykstra-Parsons method for prediction of oil recovery by water flooding is a well known technique which has been used by the petroleum industry since 1945 . The present work carries their study further, solving the same problem of calculating coverage for certain values of permeability variation having water-oil-ratio and mobility ratio as fixed parameters. The work herein, instead of using 50 layers, uses 200. Also a more precise theoretical approach to the problem is given. Because of these differences the resulting curves are slightly modified.

In a second part, we deal with empirical simplifications with considerable success. The idea was to collapse the data and curves obtained in the first part into a single curve which covers most of the range of variables commonly seen in reservoir displacements.
\end{abstract}




\section{INTRODUCTION}

The Dykstra-Parsons ${ }^{1}$ method for prediction of oil recovery by water flooding is a classic in secondary recovery. It is based on piston-like displacement of oil by water. Only water is assumed to be produced from a layer after breakthrough of the layer. A total of $\mathbf{5 0}$ layers with differing permeabilities was considered in their original study, and the result, when applied to large scale projects, closely fit waterflood recoveries. To our knowledge, up to the present time, no one has tried to verify whether their curves are correct. With the advance of computer facilities, this is not a difficult task. We decided, however, to take into account a more precise theoretical approach to calculate the values of water-oil-ratios. Also, for the sake of greater accuracy with the theory, we worked with 200 layers, rather than 50, as had been done by Dykstra and Parsons.

We recognize that the ideas embodied in the Dykstra-Parsons method are not limited to waterflooding. They will work for any recovery process where there is nearly piston-like displacement of oil by the displacing fluids.

In the second stage we developed a simplification to the curves obtained in the first stage. Many empirical relationships between the parameters were studied. We present only that method which gave the best result.

\section{MATHEMATICAL FORMATION FOR A LAYERED SYSTEM}

To illustrate the ideas involved, we first take a system of two layers initially saturated with oil and connate water, and displace these fluids with injection water from the left. After a certain period of time we would have the situation pictured below.

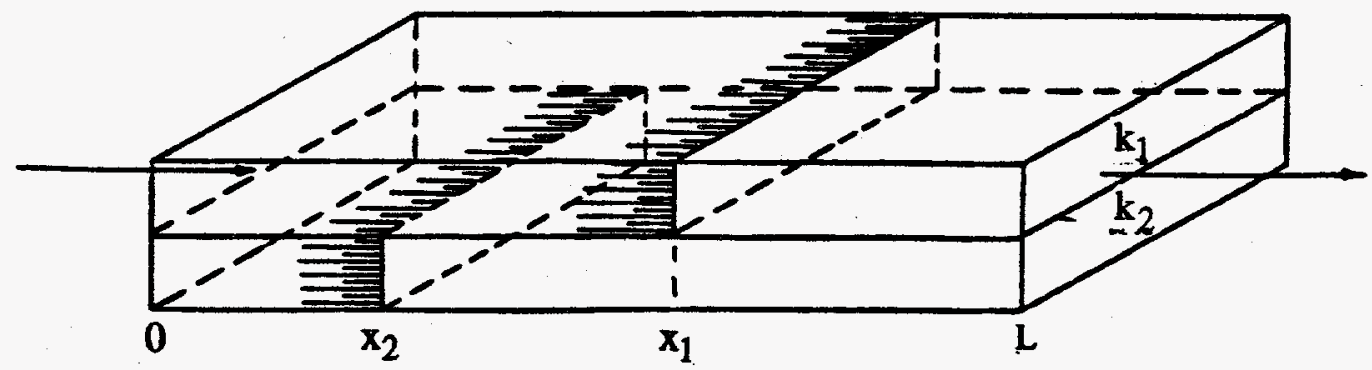

Fig. 1. Two-layered waterflood displacement. 


\subsection{PISTON-LIKE DISPLACEMENT}

To simplify the equations defining this process, we assume that:

1. Both layers have the same fluid saturations $S_{o j}, S_{w i}$, prior to water-flooding, and both layers have the same saturations, $S_{\text {or }}$, behind the water front.

2. There is no cross-flow between layers.

3. The water and oil relative permeability ratios are equal for both layers.

4. Production in both layers, at the outflow end, changes abruptly from oil to water; that is, a piston-like displacement.

It should be recognized that these assumptions are not limited to waterflood displacements. They are valid any time the displacing fluid acts in a piston-like manner in the recovery process being used. However, for simplicity the remaining narrative will focus on waterflooding, as Dykstra and Parsons did.

Applying Darcy's law to Layer 1, we have,

$$
\mathrm{v}_{1}=-\frac{\mathrm{k}_{1}\left(\Delta \mathrm{p}_{\mathrm{w}}+\Delta \mathrm{p}_{\mathrm{o}}\right)}{\frac{\mu_{\mathrm{w}} \mathrm{x}_{1}}{\mathrm{k}_{\mathrm{rw}}}+\frac{\mu_{\mathrm{o}}\left(\mathrm{L}-\mathrm{x}_{1}\right)}{\mathrm{k}_{\mathrm{ro}}}}=-\frac{\mathrm{k}_{1} \Delta \mathrm{p}}{\frac{\mu_{\mathrm{w}} \mathrm{x}_{1}}{\mathrm{k}_{\mathrm{rw}}}+\frac{\mu_{\mathrm{o}}\left(\mathrm{L}-\mathrm{x}_{1}\right)}{\mathrm{k}_{\mathrm{ro}}}}
$$

where:

$$
k_{1}=\text { absolute permeability of Layer } 1
$$

Repeating the equation for Layer 2 ,

$$
\mathrm{v}_{2}=-\frac{\mathrm{k}_{2} \Delta \mathrm{p}}{\frac{\mu_{\mathrm{w}} \mathrm{x}_{2}}{\mathrm{k}_{\mathrm{rw}}}+\frac{\mu_{0}\left(\mathrm{~L}-\mathrm{x}_{2}\right)}{\mathrm{k}_{\mathrm{ro}}}}
$$

but,

$$
v_{1}=\phi \Delta S_{w} \frac{d x_{1}}{d t}
$$

and,

$$
v_{2}=\phi \Delta S_{w} \frac{d x_{2}}{d t}
$$


Substituting Eqs. 3a and $3 \mathrm{~b}$ into Eqs. 1 and 2, and rearranging, we get,

$$
\frac{\mathrm{dx}_{1}}{\mathrm{dt}}=\frac{\mathrm{V}_{1}}{\phi \Delta \mathrm{S}_{\mathrm{w}}}=-\left[\frac{\mathrm{k}_{1} \Delta \mathrm{p}}{\frac{\mu_{\mathrm{w}} \mathrm{x}_{1}}{\mathrm{k}_{\mathrm{rw}}}+\frac{\mu_{\mathrm{o}}\left(\mathrm{L}-\mathrm{x}_{1}\right)}{\mathrm{k}_{\mathrm{ro}}}}\right] \frac{1}{\phi \Delta \mathrm{S}_{\mathrm{w}}}
$$

and,

$$
\frac{\mathrm{dx}_{2}}{\mathrm{dt}}=\frac{\mathrm{V}_{2}}{\phi \Delta \mathrm{S}_{\mathrm{w}}}=-\left[\frac{\mathrm{k}_{2} \Delta \mathrm{p}}{\frac{\mu_{\mathrm{w}} \mathrm{x}_{2}}{\mathrm{k}_{\mathrm{rw}}}+\frac{\mu_{\mathrm{o}}\left(\mathrm{L}-\mathrm{x}_{2}\right)}{\mathrm{k}_{\mathrm{ro}}}}\right] \frac{1}{\phi \Delta \mathrm{S}_{\mathrm{w}}}
$$

where:

$$
\begin{aligned}
\phi \quad= & \text { porosity } \\
\Delta S_{w}= & \text { change in water saturation between oil zone and water zone, } \\
& 1-S_{w i}-S_{o r}
\end{aligned}
$$

Rearranging Eqs. 4 and 5, and equating, we get,

$$
\frac{-\Delta \mathrm{p}}{\phi \Delta \mathrm{S}_{\mathrm{w}}}=\left[\frac{\mu_{\mathrm{w}} \mathrm{x}_{1}}{\mathrm{k}_{\mathrm{rw}}}+\frac{\mu_{\mathrm{o}}\left(\mathrm{L}-\mathrm{x}_{1}\right)}{\mathrm{k}_{\mathrm{ro}}}\right] \frac{1}{\mathrm{k}_{1}} \frac{\mathrm{dx} 1}{\mathrm{dt}}=\left[\frac{\mu_{\mathrm{w}} \mathrm{x}_{2}}{\mathrm{k}_{\mathrm{rw}}}+\frac{\mu_{\mathrm{o}}\left(\mathrm{L}-\mathrm{x}_{2}\right)}{\mathrm{k}_{\mathrm{ro}}}\right] \frac{1}{\mathrm{k}_{2}} \frac{\mathrm{dx}}{\mathrm{dt}}
$$

where the porosity and the change in water saturation are assumed to be the same for both layers. Multiplying by $k_{\mathrm{rw}} / \mu_{\mathrm{w}}$ and letting $M=k_{r w} \mu_{0} / k_{\text {ro }} \mu_{w}$, where $M$ is the mobility ratio, we have,

$$
\left[x_{i}+M\left(L-x_{1}\right)\right] k_{2} d x_{1}=\left[x_{2}+M\left(L-x_{2}\right)\right] k_{1} d x_{2}
$$

Integrating from zero to $\mathrm{L}$ for the first strip and from zero to $\mathrm{x}_{2}$ for the second strip, we get,

$$
\int_{0}^{L}\left[x_{1}+M\left(L-x_{1}\right)\right] k_{2} d x_{1}=\int_{0}^{x_{2}}\left[x_{2}+M\left(L-x_{2}\right)\right] k_{1} d x_{2}
$$

or,

$$
\frac{(1-M) x_{2}^{2}}{L^{2}}+\frac{2 M x_{2}}{L}-\frac{k_{2}}{k_{1}}(1+M)=0
$$


Solving for $\mathrm{x}_{2} / \mathrm{L}$ we have,

$$
\frac{x_{2}}{L}=\frac{-M+\sqrt{M^{2}+\left(k_{2} / k_{1}\right)\left(1-M^{2}\right)}}{1-M}
$$

Defining coverage, $\mathrm{C}$, as the fraction of the total volume of the system which has been flooded with water, we get,

$$
\mathrm{C}=\frac{1+\mathrm{x}_{2} / \mathrm{L}}{2}
$$

If there were $\mathrm{n}$ layers, at breakthrough of the first strip the equation would be,

$$
C=\frac{1+x_{2} / L+\ldots .+x_{n} / L}{n}=\frac{1+\sum_{i=2}^{n} x_{i} / L}{n}
$$

Equation 12 gives the coverage at the time water is first produced from the layer of highest permeability, $\mathbf{k}_{1}$. Using Eqs. 10 and 12, we can write,

$$
C=\frac{1+\sum_{i=2}^{n} \frac{M-\sqrt{M^{2}+\left(k_{i} / k_{1}\right)\left(1-M^{2}\right)}}{M-1}}{n}
$$

When the interface has reached the right end of the top (highest permerability) layer, the rate of water production (assuming a perfect interface) will be,

$$
\mathrm{q}_{\mathrm{w} 1}=\frac{\mathrm{A}_{1} \mathrm{k}_{1} \Delta \mathrm{p}}{\mu_{\mathrm{w}} \mathrm{L} / \mathrm{k}_{\mathrm{rw}}}
$$

And the rate of oil production from any lower permeability layer will be,

$$
\mathrm{q}_{\mathrm{oi}}=\frac{A_{\mathrm{i}} \mathrm{k}_{\mathrm{j}} \Delta \mathrm{p}}{\frac{\mu_{\mathrm{w}} \mathrm{x}_{\mathrm{i}}}{\mathbf{k}_{\mathrm{rw}}}+\frac{\mu_{\mathrm{o}}\left(\mathrm{L}-\mathrm{x}_{\mathrm{i}}\right)}{\mathrm{k}_{\mathrm{ro}}}}
$$


Therefore the producing water-oil-ratio (WOR) will be,

$$
\text { WOR }=\frac{q_{w 1}}{\sum_{i=2}^{n} q_{o i}}=\frac{A_{1} / L}{\sum_{i=2}^{n} \frac{A_{i} k_{i} / A_{1} k_{1}}{x_{i}+M\left(L-x_{i}\right)}}
$$

Substituting Eq. 10 in Eq. 16 we have,

$$
\text { WOR }=\frac{1}{\sum_{i=2}^{n} \frac{A_{i} k_{i} / A_{1} k_{1}}{\sqrt{M^{2}+\left(k_{i} / k_{1}\right)\left(1-M^{2}\right)}}}
$$

This last equation gives the producing water-oil-ratio from $n$ strips of permeabilities $\mathbf{k}_{1}, \mathbf{k}_{2} \ldots . \mathrm{k}_{\mathrm{n}}$, at the time water is first produced from layer, $k_{1}$, in terms of $k_{i} / k_{1}$ and $M$.

For the case where the $\mathrm{m}$ th layer has just been flooded through, and where $A_{1}=A_{2}=\ldots=A_{n}$, it is easy to show that Eqs. 13 and 17 become,

$$
C=\frac{m+\left(\frac{n-m}{M-1}\right) M-\frac{1}{M-1} \sum_{i=m+1}^{n} \sqrt{M^{2}+\frac{k_{i}}{k_{m}}\left(1-M^{2}\right)}}{n}
$$

and,

$$
\text { WOR }=\frac{\sum_{i=1}^{m} k_{i}}{\sum_{i=m+1}^{n} \frac{k_{i}}{\sqrt{M^{2}+\left(k_{i} / k_{m}\right)\left(1-M^{2}\right)}}}
$$

An interesting case happens when $M=1$. In this special case the equations need to be derived in a slightly different manner, but their developments are quite simple, so they will not be discussed further here.

\subsection{MODIFICATIONS TO THE CALCULATIONAL APPROACH}

It is also important to consider the case where the $m$ 'th layer is not quite completely flooded through. The coverage in the this case will be the same as when the $m$ 'th layer is completely flooded, but the water-oil-ratio is not the same. Nor is it the same as when the $(m-1)$ 'th layer has just 
been flooded out. Dykstra and Parsons did not consider this case in their study. It is important to consider this condition for with a finite number of layers, the calculated water-oil-ratios, as indicated in the figures below, proceed through a series of discrete jumps as each layer breaks through, rather than predicting a smooth curve.

The Dykstra-Parsons equations calculate the values on the tops of the stair-step curves (indicated by circles). The concept that will be described here, calculates the bottoms of these curves (indicated by triangles). With a finite number of layers, both must be calculated to generate the best smooth curve.

For this purpose, the coverage equation will remain the same as before, as indicated in Figs. 2 and 3. But the WOR equation will differ, since the $m$ 'th layer will be producing oil rather than water just prior to breakthrough of that layer. When the $m$ 'th layer has not quite broken

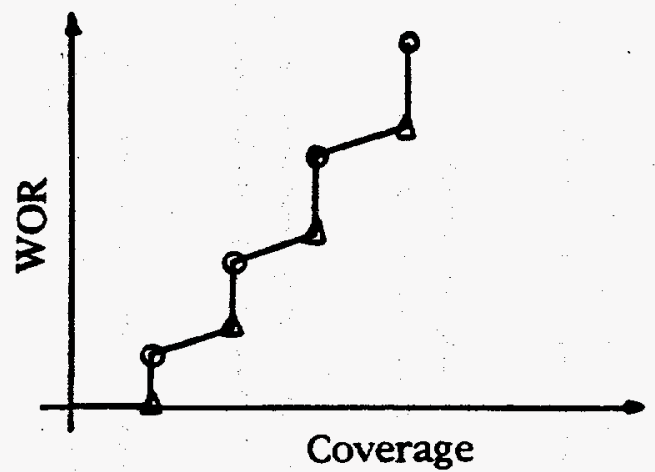

Fig. 2 Water/oil ratio history for $\mathrm{M}<1$.

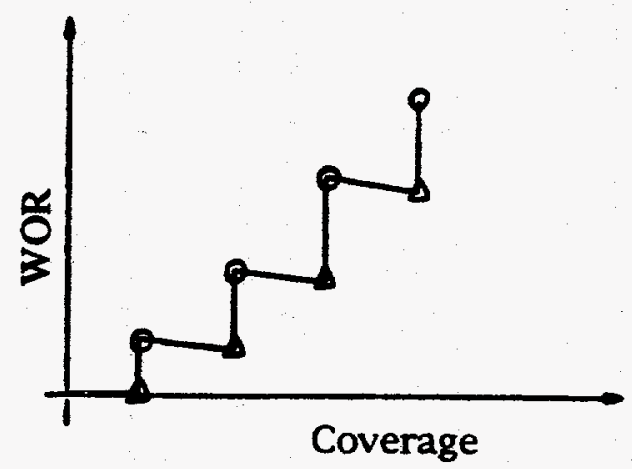

Fig. 3 Water/oil ratio history for $M>1$. 
through, Eq. 19 is changed to,

$$
\text { WOR }=\frac{\sum_{i=1}^{m-1} k_{i}}{\sum_{i=m}^{n} \frac{k_{i}}{\sqrt{M^{2}+\left(1-M^{2}\right)\left(k_{i} / k_{m}\right)}}}
$$

Note that in the numerator of Eq. 20 we do not include $\mathrm{k}_{\mathrm{m}}$, while in the denominator, we include it, because we are still producing oil from that layer.

To make smooth WOR curves, the arithematic averages of Eqs. 19 and 20 were used to define the WOR histories of all the cases studied.

\section{DYKSTRA-PARSONS PERMEABILITY DISTRIBUTION}

Dysktra and Parsons concluded that when permeability values were arranged in descending order, the distribution followed a log-normal curve, as indicated in Fig. 4. If more then one geologic unit is present, each unit presents its own characteristic log-normal curve.

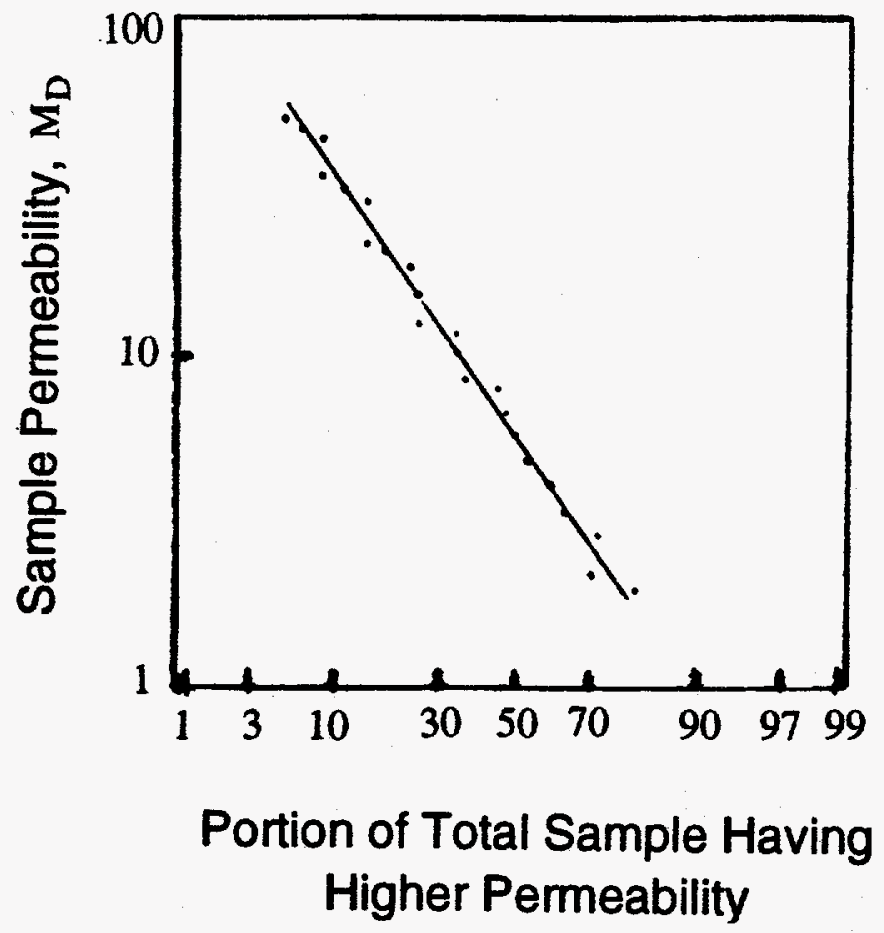

Fig. 4 Log-normal permeability distribution graph. 
This idea can be put into an equation, as follows,

$$
h_{f}=\frac{1}{2}\left[1+\operatorname{erf}\left(\frac{\log k_{i}-\log \bar{k}}{\sqrt{2 \sigma^{2}}}\right)\right]
$$

where:

$$
\begin{aligned}
& \mathbf{h}_{\mathrm{f}}=\text { cumulative fraction of cores, to value, } \mathbf{i} \\
& \mathbf{k}_{\mathrm{i}}=\text { permeability of core, } \mathbf{i} \\
& \overline{\mathbf{k}}=\text { permeability of the average core, } \mathbf{k}_{50} \\
& \boldsymbol{\sigma}= \\
& \text { standard deviation of the permeability } \\
& \text { distribution }
\end{aligned}
$$

To define the standard deviation, $\sigma$, Dykstra and Parsons defined a term they called permeability variation, $V$, as follows,

$$
\mathrm{V}=\frac{\overline{\mathrm{k}}-\mathbf{k}_{\boldsymbol{\sigma}}}{\overline{\mathbf{k}}}
$$

where:

$$
\begin{gathered}
\mathbf{k}_{\sigma}=\text { the permeability at one standard deviation on } \\
\text { the log probability graph, equal to } k_{84.13}
\end{gathered}
$$

Substituting Eq. 22 into the definition for $\sigma$, we get,

$$
\sigma \equiv \log \overline{\mathrm{k}}-\log \left(\mathrm{k}_{\sigma}\right)=-\log (1-\mathrm{V})
$$

As a result, Eq. 21 becomes,

$$
h_{f}=\frac{1}{2}\left\{1+\operatorname{erf}\left[\frac{-\log \left(k_{i} / \sqrt{k}\right)}{\sqrt{2} \log (1-V)}\right]\right\}
$$

Equation 24 can be used to calculate permeabilities of individual layers as a function of the permeability variation, $\mathrm{V}$, and of the number of layers chosen. We chose to use 200 layers to help smooth the resulting curves. To accurately calculate the value of the permeability of each layer, we used an accurate empirical algorithm from Abramowitz and Stegun ${ }^{2}$ based on the 
definition of the Gaussian distribution commonly used in statistics. For easy comparison, the results were interpolated to the same values of WOR used by Dykstra and Parsons. The resulting curves are displayed in Figs. 514 , with WOR's of $0.10,0.20,0.50,1.0,2.0,5.0,10,25,50$ and 100 .

\section{EMPIRICAL CORREIATION}

In this part of the work, we tried some simplifications on the curves. The idea was to collapse the entire set of 130 curves into a single curve that would include the parameters: Coverage, C, Permeability Variation, V , Mobility Ratio, M, and Water-Oil-Ratio, WOR. The advantage of having a single curve is obvious, since a unique equation could be fitted to it, and anyone wishing to calculate Coverage knowing the other parameters could do it simply, without needing to use a large set of curves. A hand calculator could be used to produce answers in a few seconds.

Many correlation techniques were tried. The best we found was to graph WOR on logarithmic coordinates against Coverage on arithmetic coordinates. An example of these curves is shown, at a permeability variation (V) of 0.5 , in Fig. 15. Note that the upper and right-hand parts of these curves have similar shapes. They can be moved vertically in such a way that they fall nearly on top of each other.

The lower parts of the curves do not fit with each other in this way. We found, however, that if we add a constant to the value of WOR the curves did have similar shapes over larger portions of their ranges. Constants ranging from 0.1 to 0.5 were tried, and it was fond that a value of 0.4 gave the best fit of the data. This idea is shown, as an example, in Fig. 16. In this figure, the shapes of the curves are similar except at very low WOR's at a high mobility ratio $(M>10)$.

The shapes of these curves were also similar at other values of permeability variation, $V$, ranging from 0.3 to 0.8 . We found that $V$ 's equal to 0.2 and 0.9 did not fit the data as accurately. But these values of $\mathrm{V}$ are outside the range normally seen in reservoirs.

Since the curves now had similar shapes on semilog paper, it only remained to correlate them as functions of WOR, permeability variation, $V$, and mobility ratio, $M$. The resulting match equations were a bit 


\section{Coverage as a Function of Permeability Variation and Mobility Ratio}

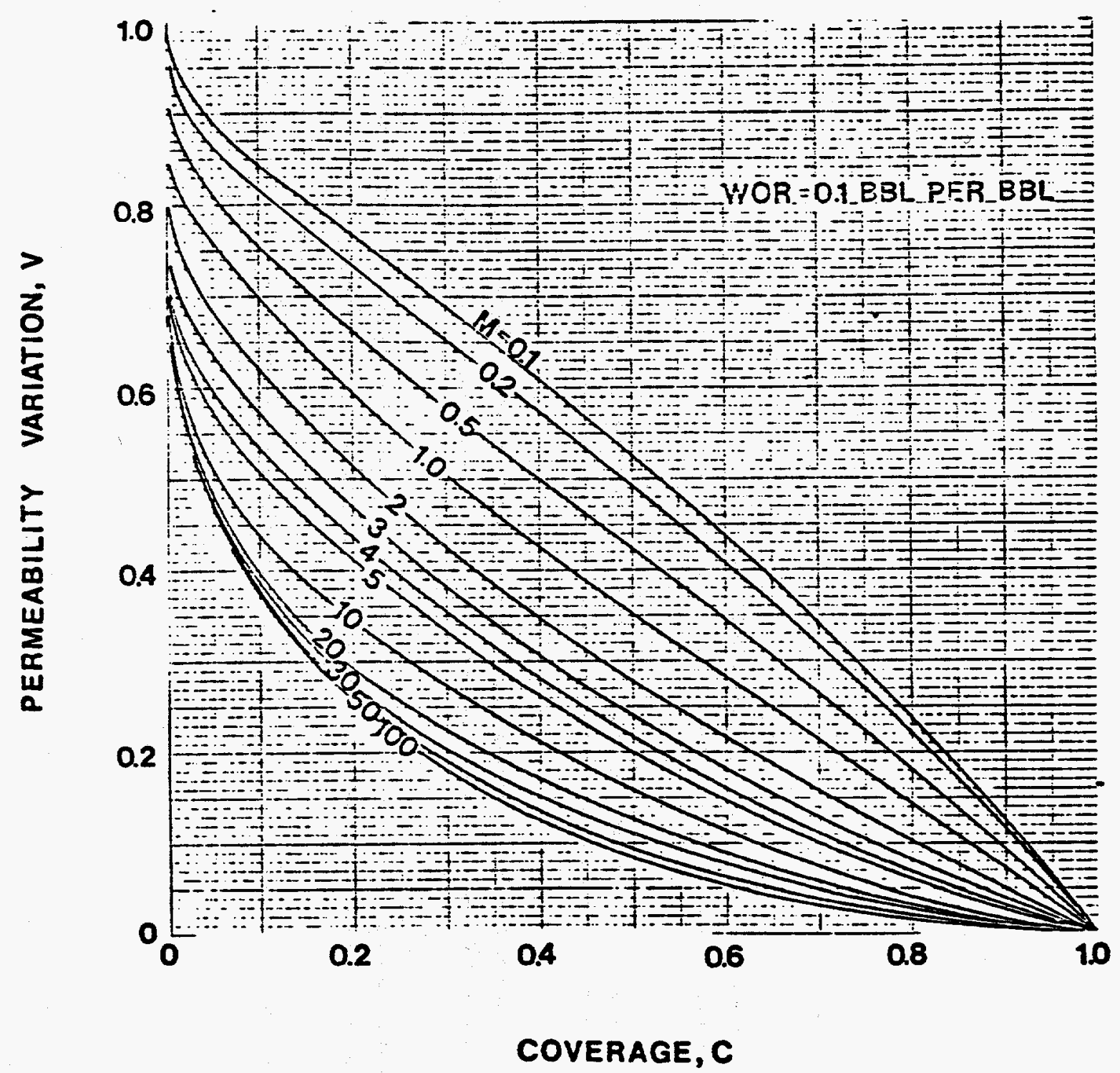

Fig. 5. Coverage curves for $\mathrm{WOR}=0.1$. 


\section{Coverage as a Function of Permeability Variation and Mobility Ratio}

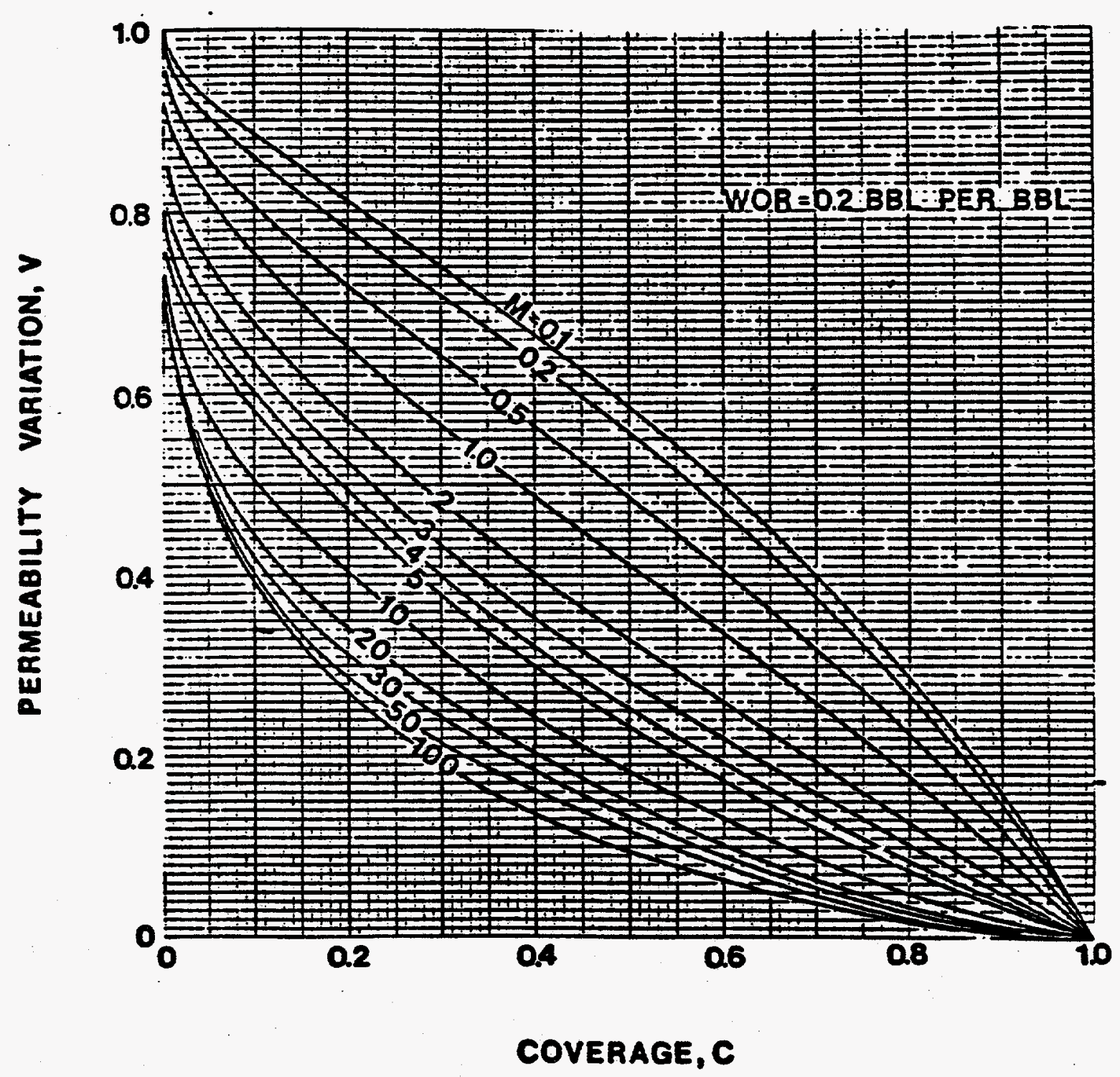

Fig. 6. Coverage curves for $\mathrm{WOR}=0.2$. 


\section{Coverage as a Function of Permeability Variation and Mobility Ratio}

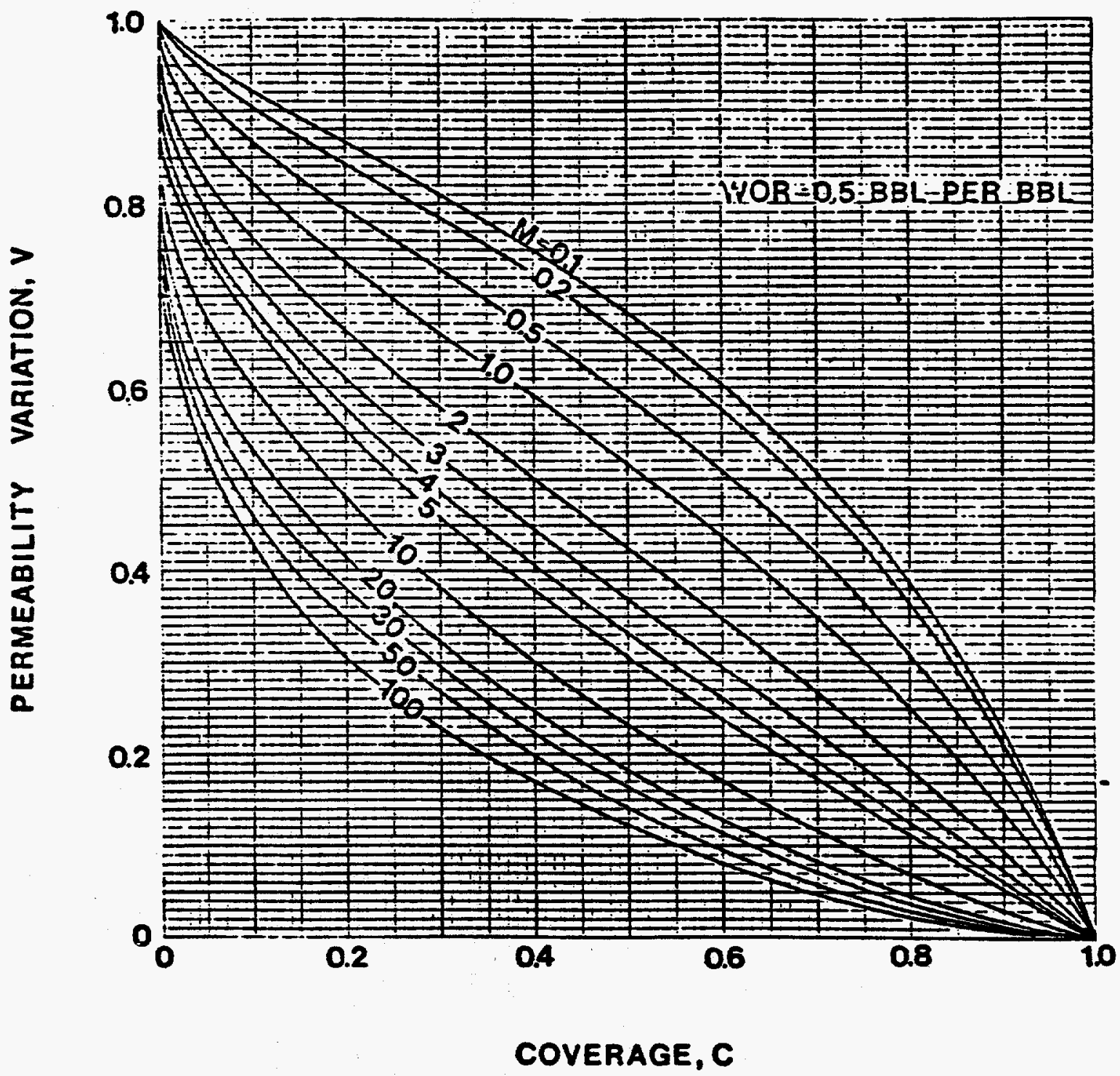

Fig. 7 Coverage curves for $\mathrm{WOR}=\mathbf{0 . 5}$. 


\section{Coverage as a Function of Permeability Variation and Mobility Ratio}

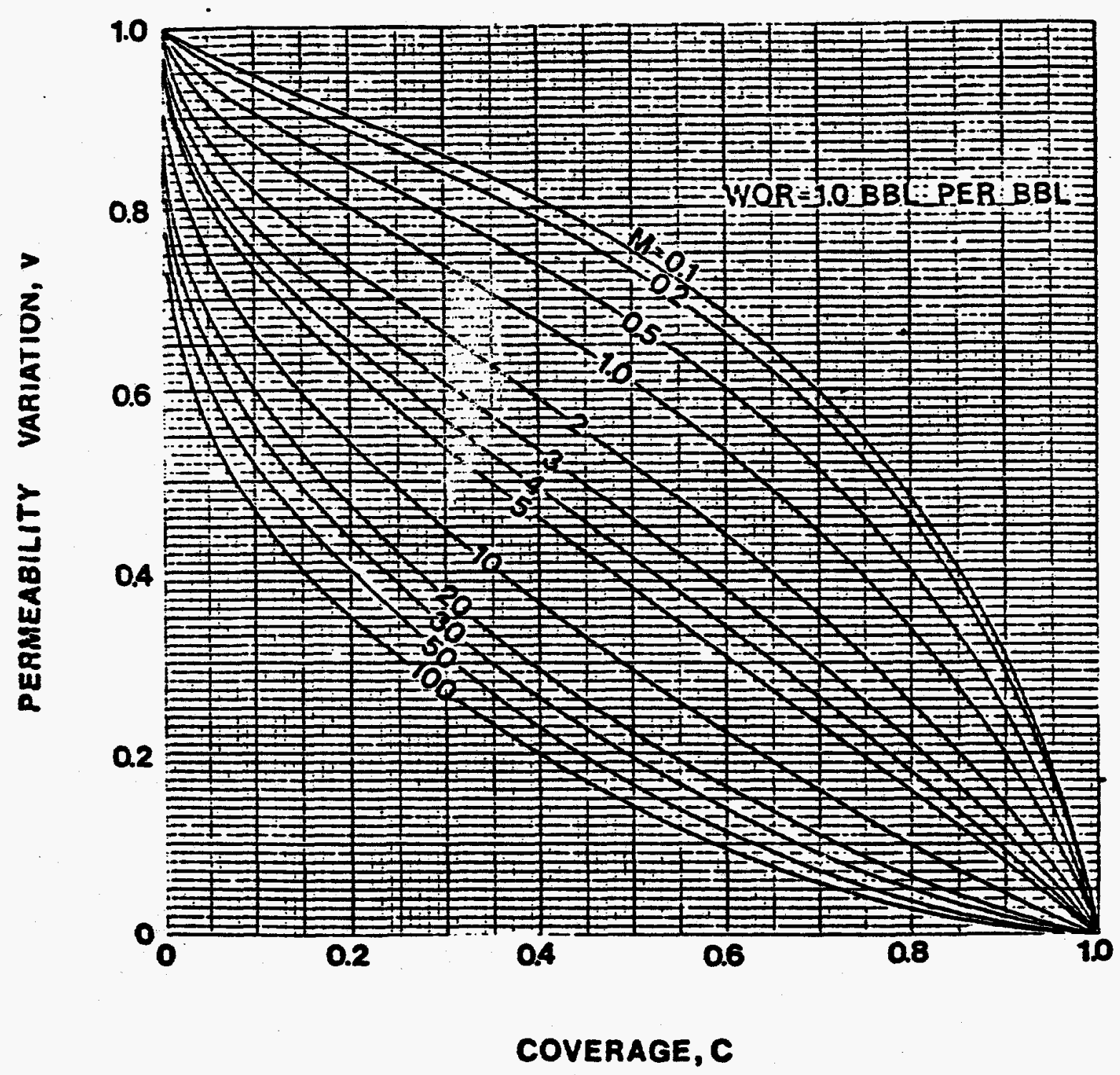

Fig. 8. Coverage curves for $W O R=1.0$. 


\section{Coverage as a Function of Permeability Variation and Mobility Ratio}

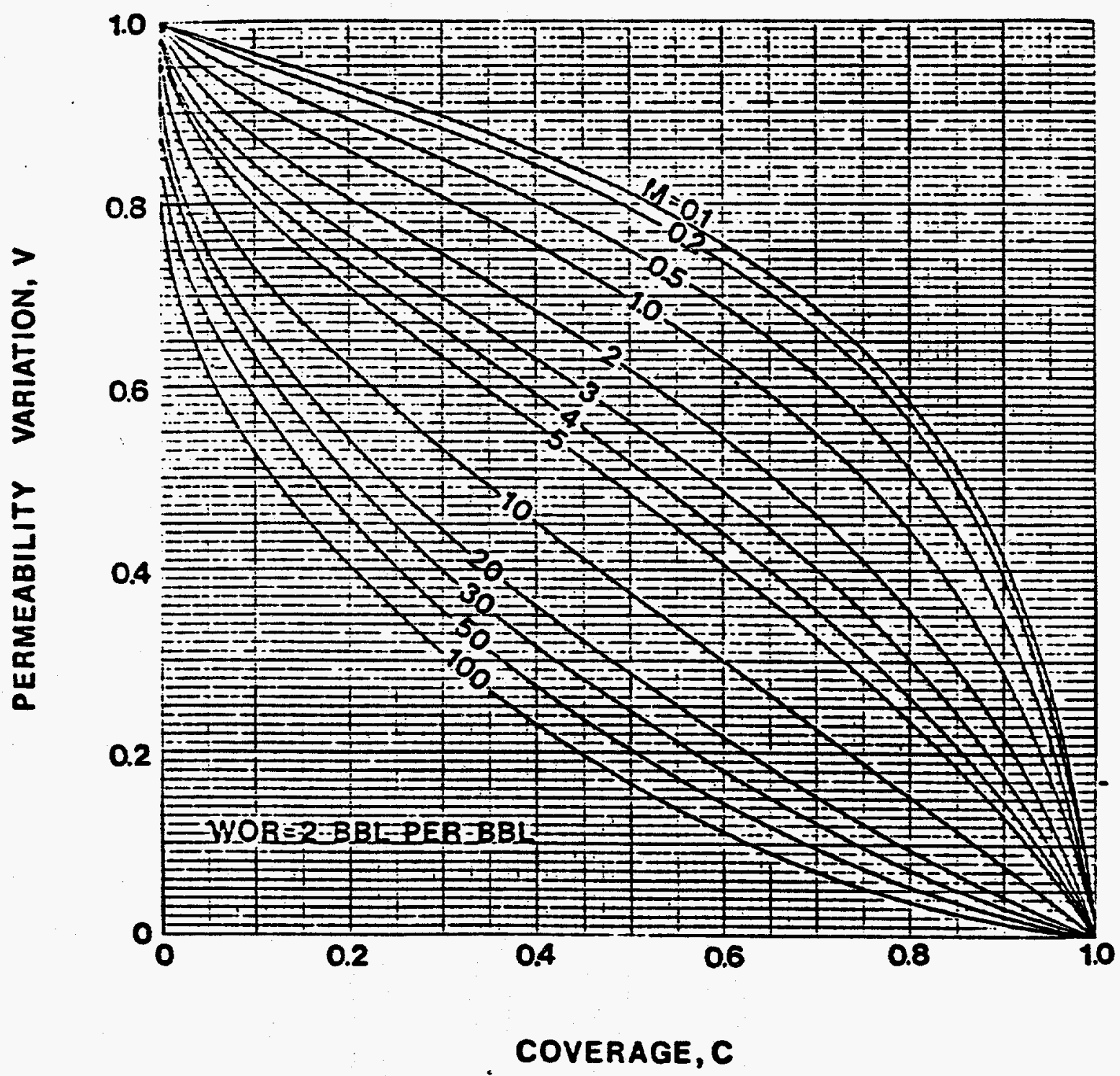

Fig. 9. Coverage curves for $\mathrm{WOR}=2$. 


\section{Coverage as a Function of Permeability Variation and Mobility Ratio}

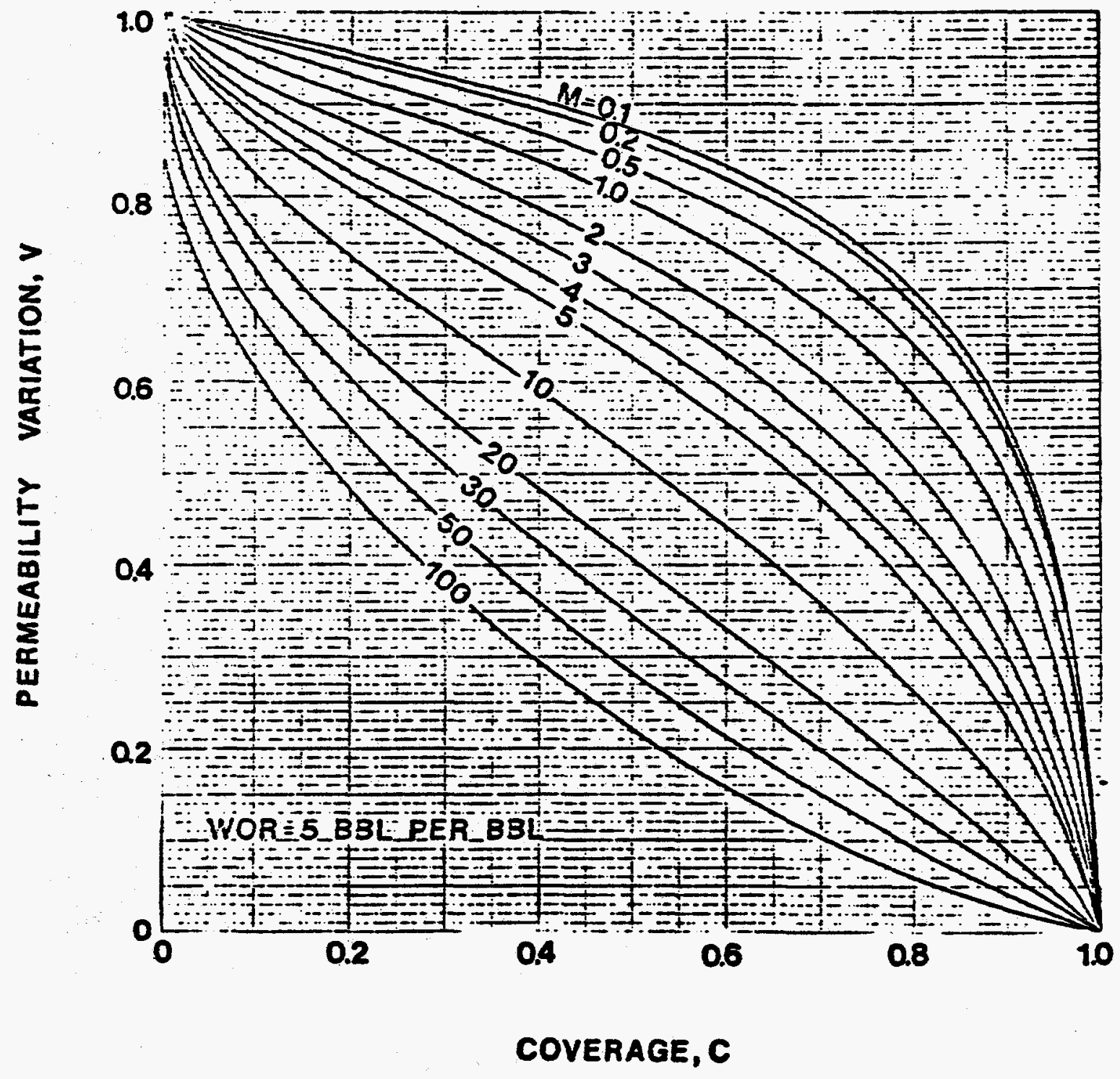

Fig. 10. Coverage curves for $W O R=5$. 


\section{Coverage as a Function of Permeability Variation and Mobility Ratio}

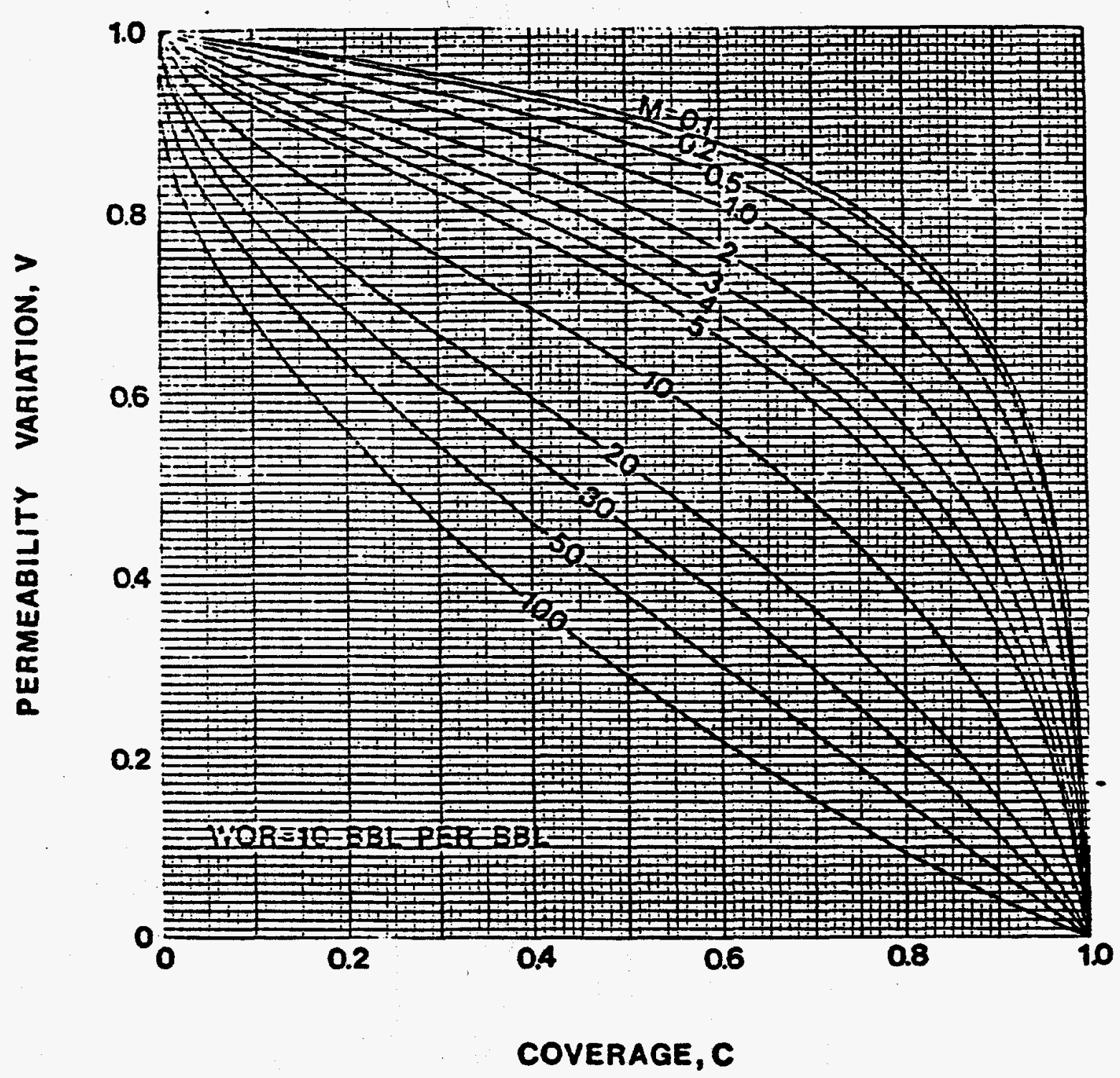

Fig. 11. Coverage curves for $W O R=10$. 


\section{Coverage as a Function of Permeability Variation and Mobility Ratio}

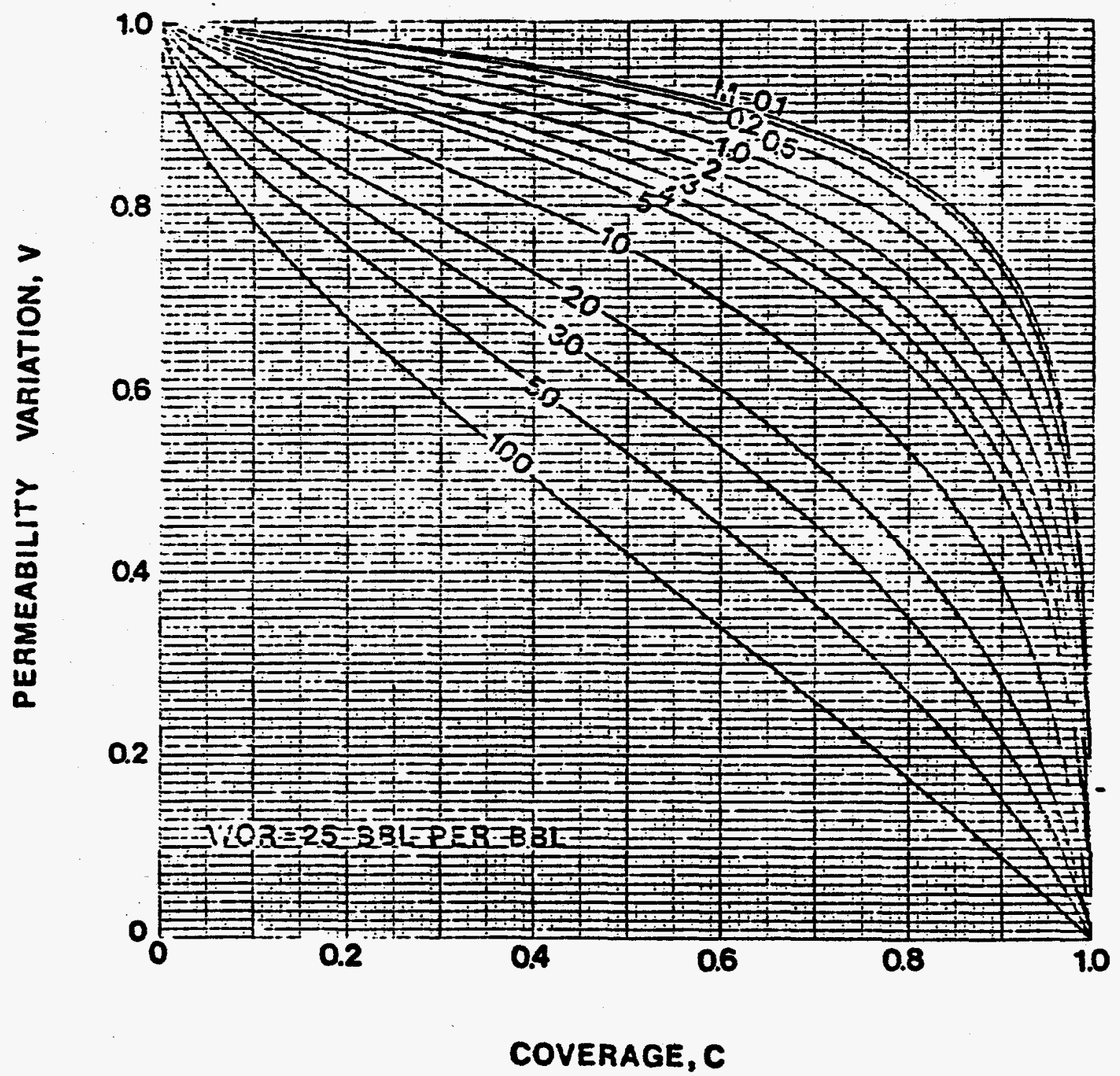

Fig. 12. Coverage curves for $\mathrm{WOR}=25$. 


\section{Coverage as a Function of Permeability Variation and Mobility Ratio}

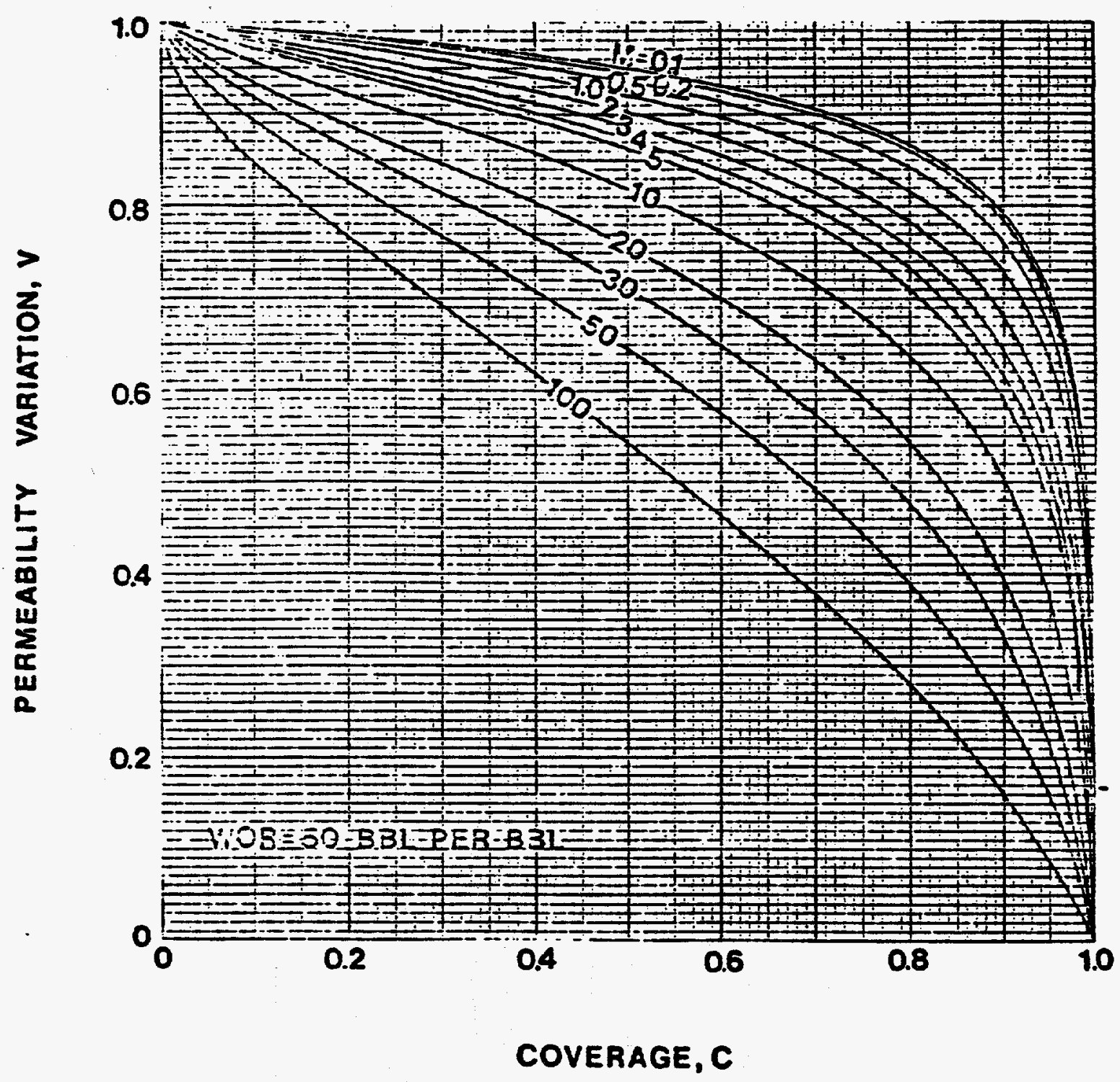

Fig. 13. Coverage curves for $\mathrm{WOR}=50$. 


\section{Coverage as a Function of Permeability Variation and Mobility Ratio}

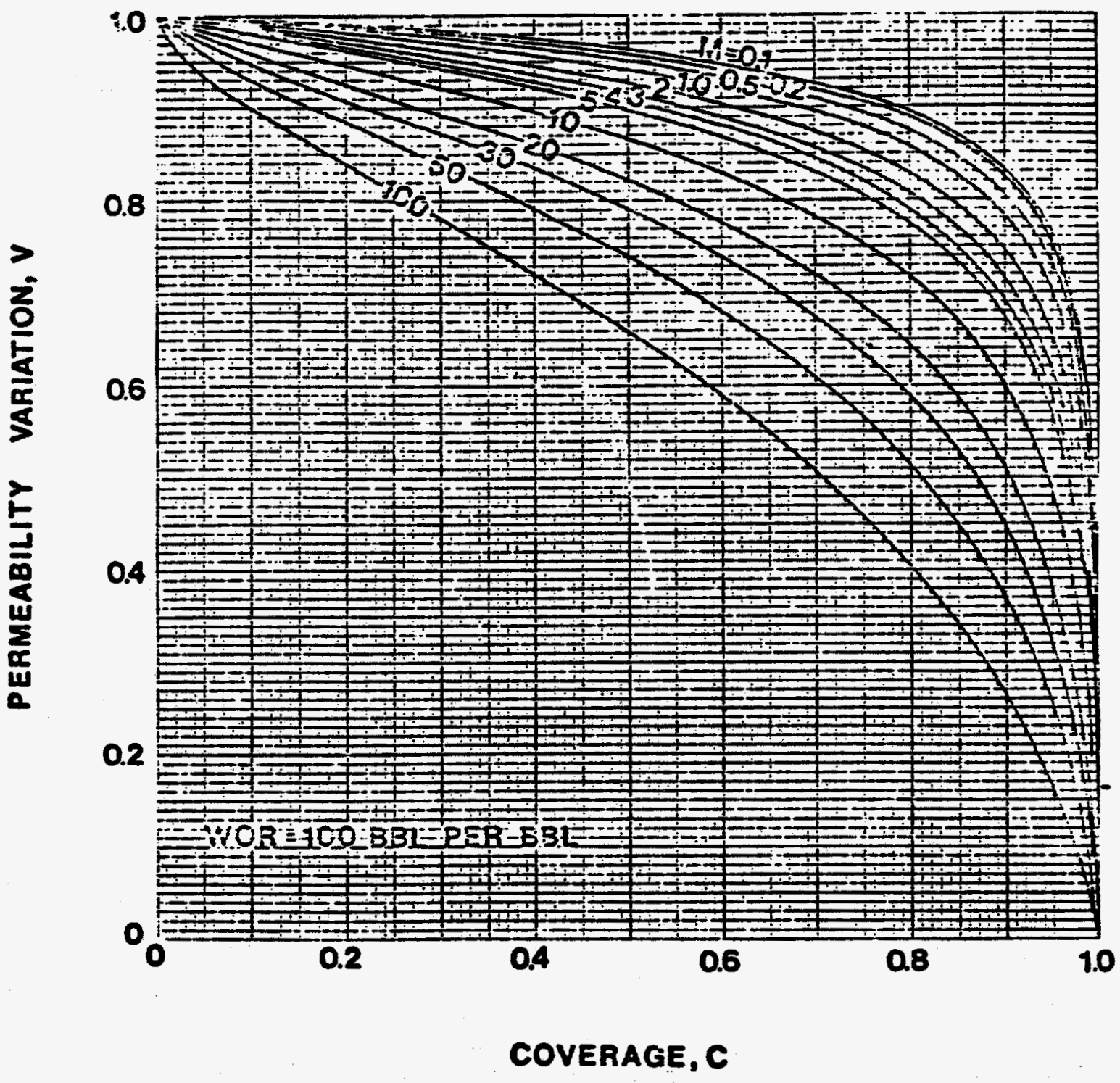

Fig. 14. Coverage curves for $W O R=100$. 


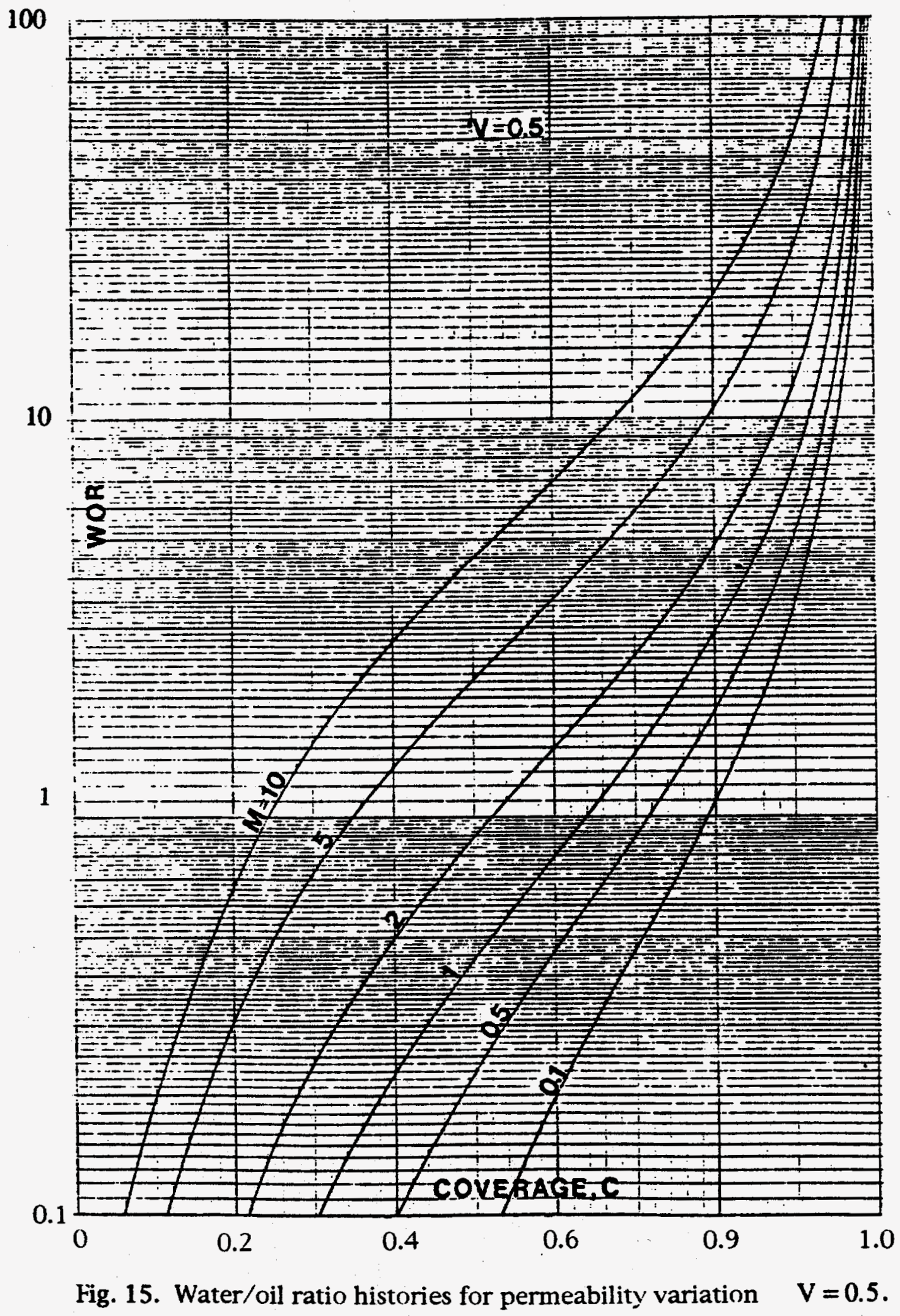




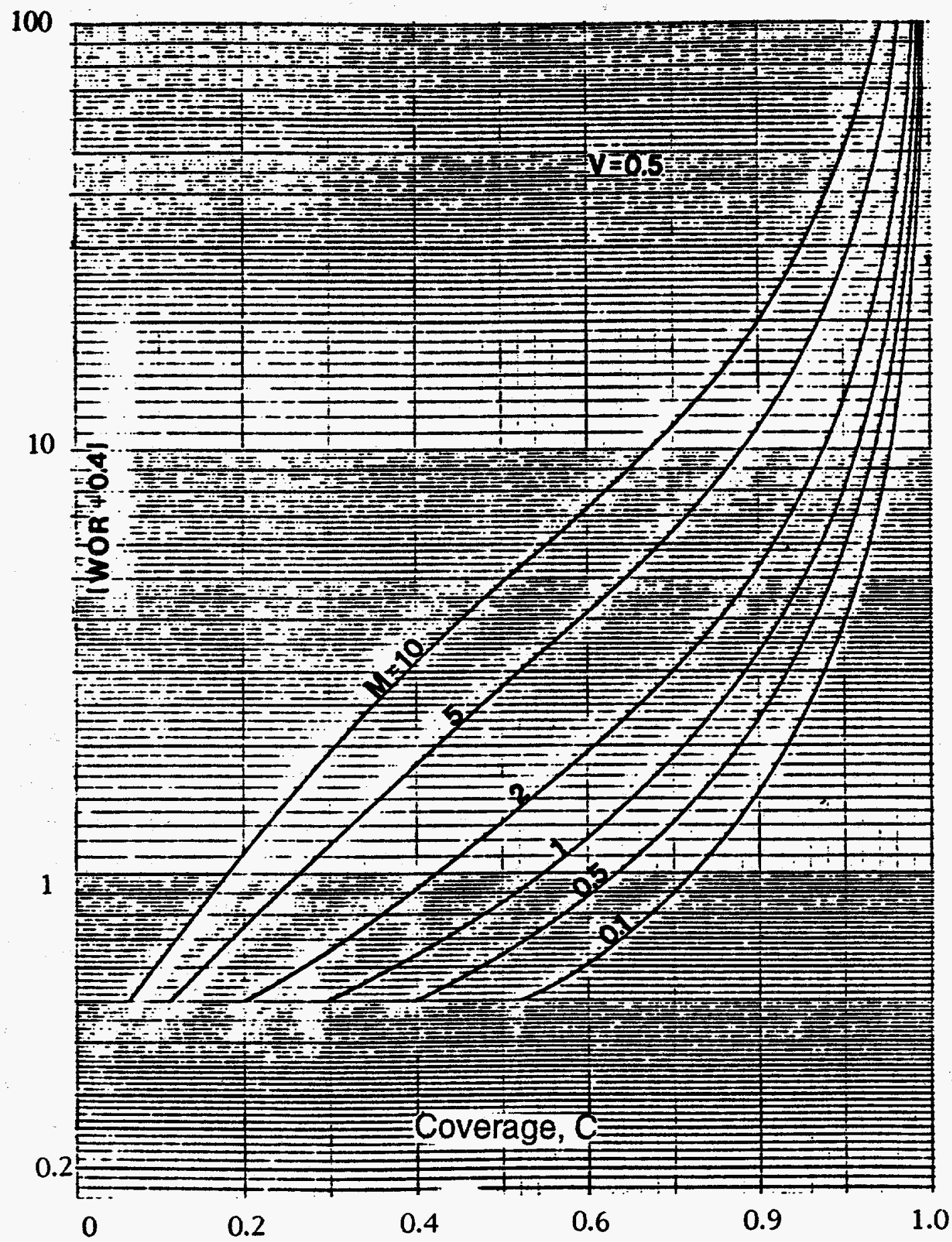

Fig. 16. Effect of adding 0.4 to water/oil ratio curves, $V=0.5$. 
complex, being partly linear and partly semi-logarithmic, but the result fit the data well, and is displayed in Fig. 17. Notice that the correlating parameter, the $y$ axis, is,

$$
y=\frac{(\text { WOR }+0.4)(18.948-2.999 V)}{(M+1.13702-0.80943 V) 10^{-0.6891+0.9735 V-1.6453 V^{2}}}
$$

The various terms, WOR, $M$ and $V$ in this complex coordinate are the result of the correlating procedure discussed above.

The curve in Fig. 17 was later fitted to an empirical equation by Fassihi. 3 The equation he found was as follows,

$$
y=3.334 C^{0.7737}(1-C)^{-1.226}
$$

This equation fit the curve of Fig. 17 almost exactly. Thus, by combining Eqs. 25 and 26, a simple hand-held calculator program can be used to calculate the recovery history of a waterflood, both rapidly and easily.

Since this correlation is empirical, it seems worthwhile to assess its accuracy, using the results of Figs. 5-14 as a basis. To test this, we checked permeability variation, $\mathrm{V}$, values of $0.3,0.5$ and 0.7 ; at WOR's ranging from 1 to 25; and $M$ from 0.1 to 10 ; for a total of 60 points. The greatest errors in these results were two points which gave errors of 6 and $8 \%$, and a few others which were slightly greater than $2 \%$ in error. These all occurred at very low WOR's where the errors are not too important from an overall recovery history point of view. The overall standard deviation of the correlation for all 60 data points was $1.81 \%$, a very good result, indeed. A simple computer program which expresses this correlation analytically was published by Fassihi. 3 


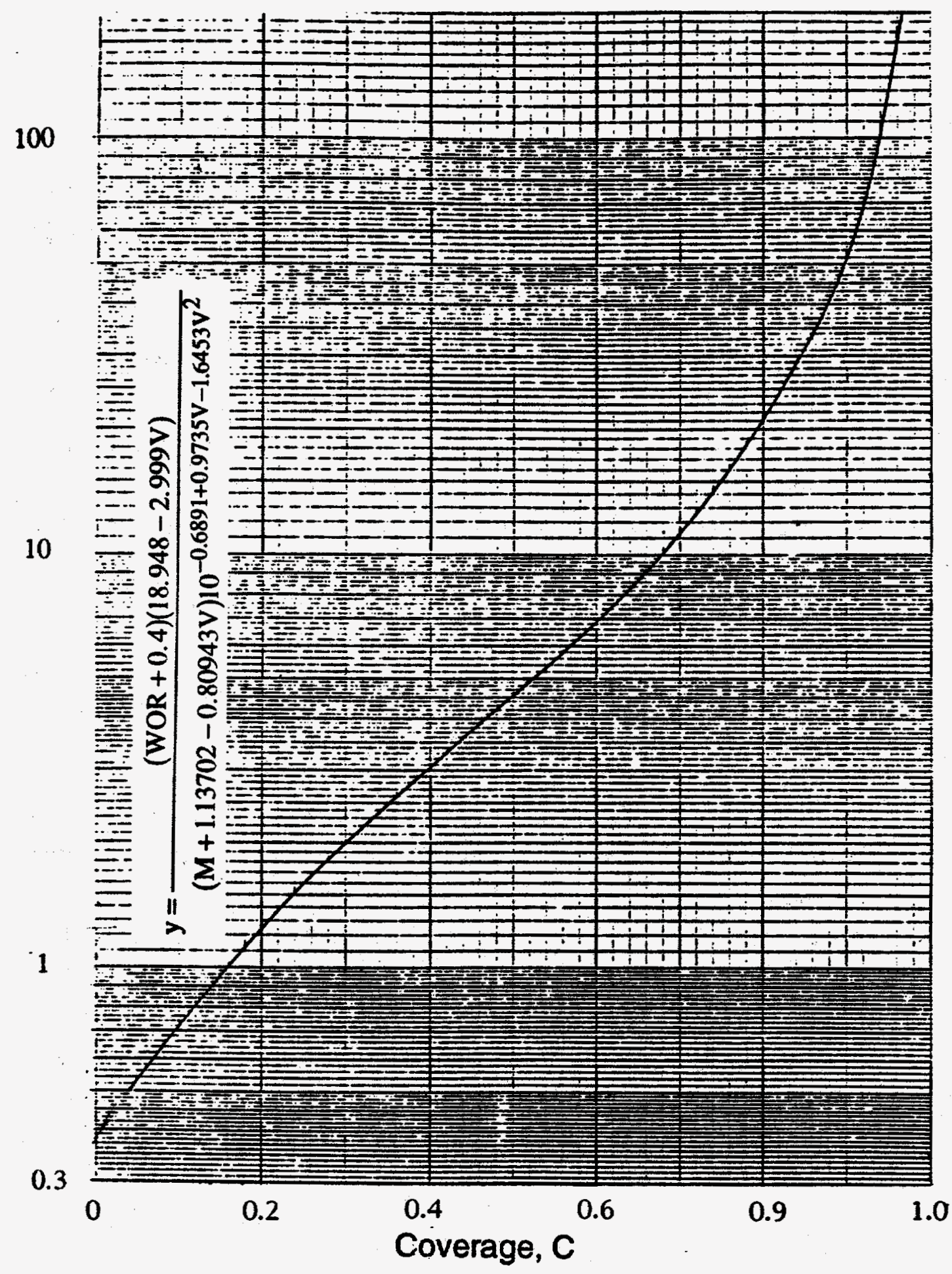

Fig. 17. Final correlation of Dykstra-Parsons recovery curves. 


\section{CONCLUSIONS}

As a result of the work discussed here, the following conclusions can be drawn.

1. The more precise calculation techniques used here modified the Dykstra-Parsons curves slightly. These revised curves are shown in detail.

2. It was possible to empirically correlate these curves into a single curve which can be used in an equation to calculate coverage over a broad range of parameters. The Permeability Variation, $V$, can range from 0.3 to 0.8 , the Mobility Ratio, $M$, can range from 0.1 to 10 , and the water-oil ratio, WOR, from 1 to 100 .

3. In this correlation, low WOR's of $\mathbf{1 . 0}$ show greater errors in predicting Coverage (up to $8 \%$ in error), but higher values of WOR produce errors of less than $2 \%$ over the entire range of the correlation's validity.

\section{REFERENCES}

1. Dykstra, H. and Parsons, R.L.: "The Prediction of Oil Recovery by Waterflood," Secondary Recovery of Oil in the United States, second edition, API, Dallas (1950) 160-74.

2. Abramowitz, M., and Stegun, L.A., "Handbook of Mathematical Functions."

3. Fassihi, M.R., "New Correlations for Calculation of Vertical Coverage and Areal Sweep Efficiency," SPERE 1, No. 6 (November 1986) 604-606. 


\section{NOMENCLATURE}

A Cross sectional area of layer

C Dykstra-Parsons coverage

erf Error function

$h_{f}$ Cumulative fraction of cores in permeability distribution graph

k Permeability

$\overline{\mathbf{k}} \quad$ Average permeability, $\mathbf{k}_{50}$

$\mathbf{k}_{\boldsymbol{\sigma}} \quad$ Permeability at one standard derivation, $\mathbf{k}_{\mathbf{8 4 . 1 3}}$

L Total length of layer

M Mobility ratio, $\mathbf{k}_{\mathrm{rw}} \mu_{\mathrm{o}} / \mathrm{k}_{\mathrm{ro}} \mu_{\mathrm{w}}$

$m$ Index on layer number

n Total number of layers

$\Delta S_{\mathrm{w}} \quad$ Change in water saturation

$t$ time

q Flow rate

V Dykstra-Parsons permeability variation

v Darcy velocity

WOR Water/oil ratio

$\mathrm{x}$ Horizontal distance

$\mu \quad$ Viscosity

$\phi$ Porosity

$\Delta \mathrm{p} \quad$ Pressure drop

$\sigma \quad$ Standard deviation of permeability distribution

\section{Subscripts}

i Individual layer

m Index on layer number

n Total number of layers

r relative

w water

o oil

1 Layer one

$2 \quad$ Layer two 